\title{
A Patent Accessory Pancreatic Duct Prevents Pancreatitis following Endoscopic Retrograde Cholangiopancreatography
}

\author{
Taku Tabata Terumi Kamisawa Kensuke Takuma Hajime Anjiki Naoto Egawa \\ Department of Internal Medicine, Tokyo Metropolitan Komagome Hospital, Tokyo, Japan
}

\section{Key Words}

Accessory pancreatic duct • Acute pancreatitis • Endoscopic retrograde pancreatography $\cdot$ Minor duodenal papilla $•$

Pancreatitis

\begin{abstract}
Background/Aim: Pancreatitis is the most common and feared complication of endoscopic retrograde cholangiopancreatography (ERCP). We previously examined patency of the accessory pancreatic duct (APD) by dye injection endoscopic retrograde pancreatography (ERP). APD patency was found in $43 \%$ of 291 control cases who had no particular changes in the head of the pancreas compared to only $6 \%$ in patients with acute pancreatitis. APD patency was closely related with the shape of the terminal portion of the APD. This study aimed to clarify whether patency of the APD prevents post-ERCP pancreatitis. Methods: We examined retrospectively the terminal shape of the APD by ERP in 34 patients with post-ERCP pancreatitis. Based on these data, patency of the APD was estimated from its terminal shape in patients with post-ERCP pancreatitis. Results: The stick-type APD $(p<0.01)$, which indicated high patency, was less frequent, and the branch-type APD ( $p<0.01)$ and halfway-type APD, or no APD ( $p<0.01)$, which showed quite low patency, were more frequent in patients with post-ERCP pancreatitis compared with controls. Accordingly, the estimated patency of the APD in post-ERCP pancreatitis patients was only $16 \%$, which was significantly lower than the $43 \%$ in controls. There was no significant relationship between the estimated APD
\end{abstract}

\section{KARGER}

Fax +4161306 1234

E-Mail karger@karger.ch

www.karger.com (c) 2010 S. Karger AG, Basel

$0253-4886 / 10 / 0272-0140 \$ 26.00 / 0$

Accessible online at:

www.karger.com/dsu patency and the severity of post-ERCP pancreatitis. Conclusions: The estimated APD patency was significantly lower in patients with post-ERCP pancreatitis. A patent APD may function as a second drainage system to reduce the pressure in the main pancreatic duct and prevent post-ERCP pancreatitis.

Copyright $\odot 2010$ S. Karger AG, Basel

\section{Introduction}

Pancreatitis is the most common and feared complication of endoscopic retrograde cholangiopancreatography (ERCP), occurring in $1.8-6.7 \%[1,2]$ of patients undergoing ERCP. It is associated with substantial morbidity and occasional mortality. There have been ongoing efforts to minimize the incidence and severity of postERCP pancreatitis. Recognition of high-risk cases in whom ERCP should be avoided, if possible, or in whom protective endoscopic or pharmacologic interventions should be considered, is useful to prevent post-ERCP pancreatitis. The mechanisms that lead to post-ERCP pancreatitis are not fully clarified, but believed to be multifactorial.

The pancreatic-duct system is formed embryologically from the ventral and dorsal pancreatic primordium. The accessory pancreatic duct (APD) is the main duct of the dorsal pancreatic primordium in the embryo and enters the duodenum through the minor duodenal papilla $[3,4]$. The APD is sometimes obliterated near the duode- 

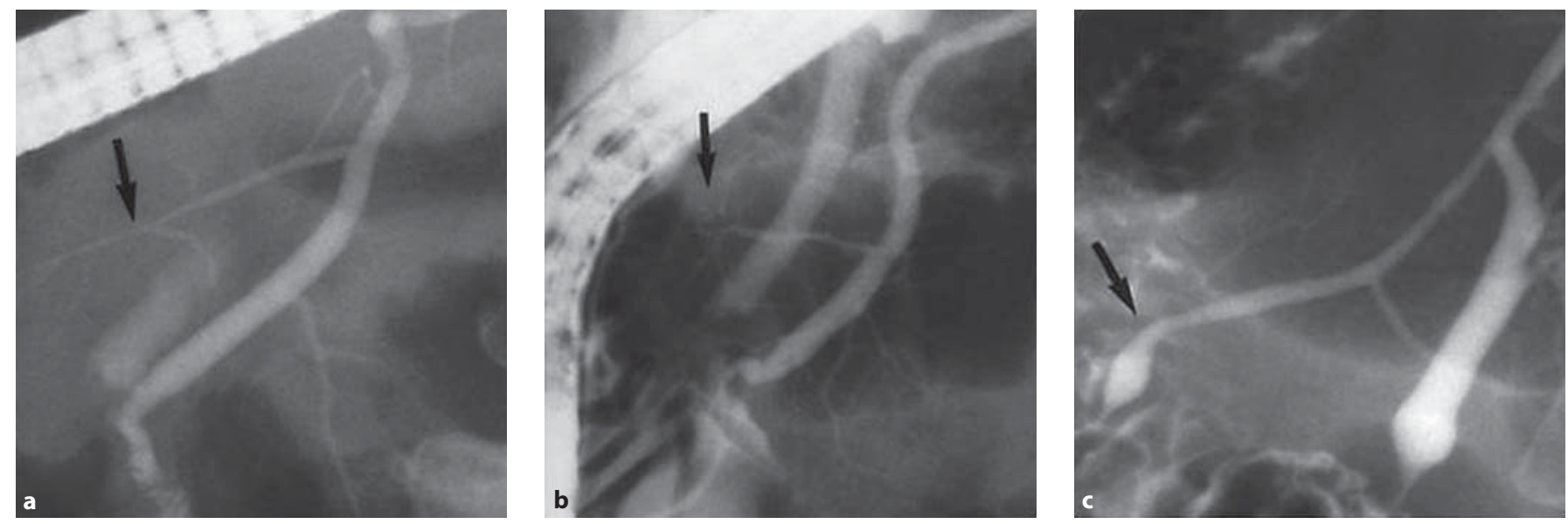

Fig. 1. Terminal shape of the different APD types: stick (a), branch (b), spindle (c), saccular (d), and cudgel (e).
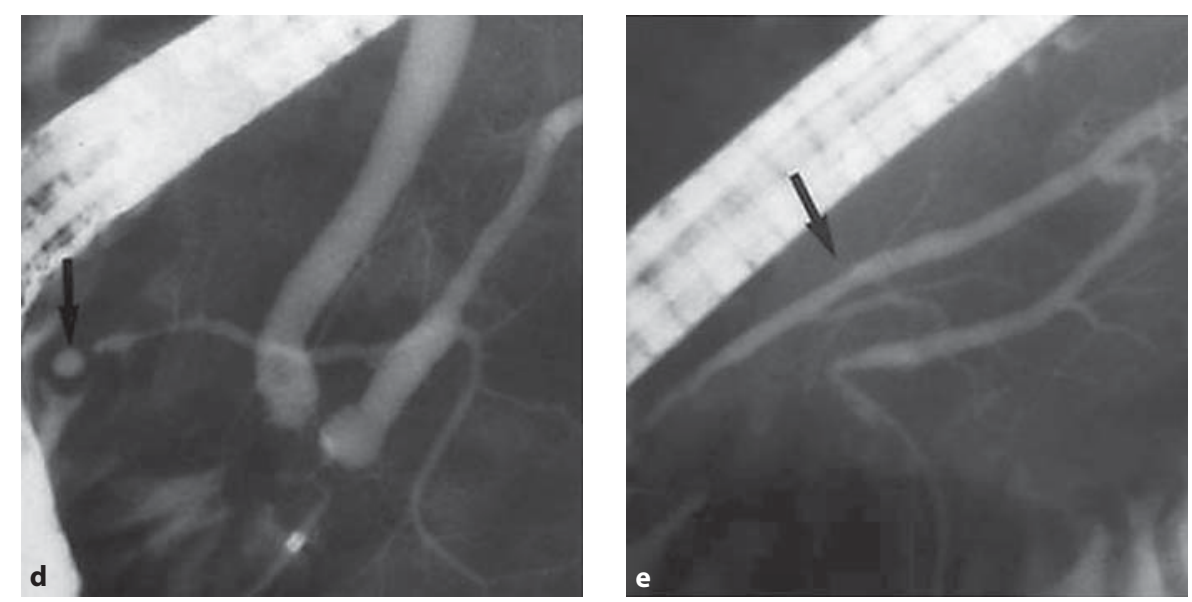

num during embryonic development, and its role in pancreatic pathophysiology has not been determined yet.

We previously examined the patency of the APD by dye injection during endoscopic retrograde pancreatography (ERP) as follows: during ERP, 2 or $3 \mathrm{ml}$ of contrast medium containing indigo carmine were injected via a catheter in the main pancreatic duct with the usual pressure, and dye excretion from the minor duodenal papilla was observed endoscopically. Failure to observe dye emerging from the minor duodenal papilla indicated obliteration. In each patient, several pancreatograms of the head of the pancreas were taken in the prone and slightly oblique positions to best demonstrate the APD. Using dye injection ERP, we previously demonstrated the close relationship between the terminal shape of the APD and its patency in 291 control cases. We also found that patency of the APD was significantly lower in 46 patients with acute pancreatitis than in controls [5-7]. To examine whether patency of the APD prevents post-ERCP pancre- atitis, we retrospectively determined patency of the APD in patients with post-ERCP pancreatitis based on the previous data by dye injection ERP.

\section{Patients and Methods}

\section{Dye Injection ERP}

Between 1989 and 2002, 410 patients underwent conventional ERP followed by dye injection ERP. Of the 291 control cases with normal pancreatogram in the head of the pancreas who underwent ERCP on suspicion of pancreatobiliary disease other than acute pancreatitis, $43 \%$ had a patent APD. The terminal shape of the APD exhibited several consistent radiological features, which were classified into six types. The most common gradually narrowing duct was observed in 140 cases (stick type; fig. 1a). In the branch-type APD, the duct gradually narrowed and gave off several fine terminal branches (fig. 1b). In the spindle-type APD, ampullary termination was seen (fig. 1c), while the saccular-type APD displayed saccular termination (fig. 1d). The cudgel-type APD is associated with a duct diameter exceeding $2 \mathrm{~mm}$ (fig. 1e). In 26 cases, the APD is halfway or none. The terminal shape of 
Table 1. Estimated APD patency of patients with post-ERCP pancreatitis and controls

\begin{tabular}{|c|c|c|c|c|}
\hline \multirow[t]{2}{*}{$\begin{array}{l}\text { Terminal shape } \\
\text { of the APD }\end{array}$} & \multicolumn{2}{|c|}{$\begin{array}{l}\text { Controls } \\
(n=291)\end{array}$} & \multicolumn{2}{|c|}{$\begin{array}{l}\text { Post-ERCP pancreatitis } \\
(\mathrm{n}=34)\end{array}$} \\
\hline & $\mathrm{n}$ & $\begin{array}{l}\text { patency } \\
\%\end{array}$ & $\mathrm{n}$ & $\begin{array}{l}\text { estimated number of } \\
\text { patent APD cases }\end{array}$ \\
\hline Stick type & 149 & 48 & 9 & $9 \times 0.48=4.3^{*}$ \\
\hline Branch type & 42 & 7 & 13 & $13 \times 0.07=0.9^{*}$ \\
\hline Spindle type & 29 & 93 & 0 & 0 \\
\hline Cudgel type & 24 & 88 & 0 & 0 \\
\hline Saccular type & 21 & 14 & 2 & $2 \times 0.14=0.3^{*}$ \\
\hline Halfway or none & 26 & 0 & 10 & 0 \\
\hline Total & 291 & 43 & 34 & 5.5 \\
\hline Estimated APD patency & & & & $5.5 / 34(16 \%)^{* *}$ \\
\hline
\end{tabular}

${ }^{*} \mathrm{p}<0.01$ vs. frequency in controls, ${ }^{* *} \mathrm{p}<0.01$ vs. patency in controls $(43 \%)$. the APD was correlated with APD patency. The stick-type APD was patent in $48 \%$ of the cases. Patency of the spindle-type APD (93\%) and cudgel-type APD (88\%) was significantly higher than that of the stick-type APD $(\mathrm{p}<0.01)$. Patency of the branch-type APD (7\%) and saccular-type APD (14\%) was significantly lower than that of the stick-type APD (p<0.01; table 1) [7].

Analysis of the APD Patients with Post-ERCP Pancreatitis

We reviewed pancreatograms with satisfactory visualization, in which contrast medium filled the first side branches, of 34 patients (10 males and 24 females) who developed acute pancreatitis after ERCP performed to examine biliary $(\mathrm{n}=13)$ and pancreatic diseases $(n=21)$. Post-ERCP pancreatitis was diagnosed in case of new onset or exacerbation of abdominal pain for $>24 \mathrm{~h}$ which was associated with an increase in serum amylase level of at least three times greater than the upper limit of normal in the next morning. Acute pancreatitis was staged as severe $(n=2)$, moderate $(n=4)$, and mild ( $\mathrm{n}=28$ ), according to a new staging system for acute pancreatitis [8]. Based on the previous data, APD patency was estimated in these 34 patients with post-ERCP pancreatitis.

\section{Statistical Analysis}

Data in this study were compared with those of controls previously analyzed using dye injection ERP. Statistical analysis was performed using Fisher's exact test. In all tests, corrected p values $<0.05$ were considered statistically significant.

\section{Results}

The stick-type APD ( $<<0.01)$, which showed high patency, was less frequent, and the branch-type APD ( $<<$ $0.01)$ and the halfway-type, or no APD ( $<<0.01)$, which showed quite low patency, were more frequent in patients with post-ERCP pancreatitis compared with 291 control cases.
Based on the data, APD patency was estimated from the terminal shape of the APD on ERP. The estimated APD patency in 34 patients with post-ERCP pancreatitis was $16 \%$, which was significantly lower than that in controls $(43 \%$; $p<0.01$; table 1$)$. The estimated APD patency was $15 \%$ in patients who developed pancreatitis after ERCP for examination of biliary diseases $(n=13)$, and $17 \%$ in those with post-ERCP pancreatitis for examination of pancreatic diseases $(n=21)$. APD patency was estimated to be $5 \%$ in patients with severe post-ERCP pancreatitis $(n=2), 8 \%$ in those with moderate post-ERCP pancreatitis $(\mathrm{n}=4)$, and $18 \%$ in those with mild postERCP pancreatitis $(n=28)$. There was no significant relationship between the severity of post-ERCP pancreatitis and the estimated APD patency.

\section{Discussion}

Dye injection ERP is a simple and definitive method for examining APD patency. APD patency was $43 \%$ in control cases using dye injection ERP, which was consistent with the average patency reported previously $[3,4]$. The terminal shape of the APD exhibited several consistent radiological features, which has been classified into six types. The terminal shape of the APD was correlated with APD patency. The spindle- and cudgel-type APD showed higher patency, but the branch- and sacculartype APD showed lower patency than the stick-type APD. We also found that patency of the APD in patients with acute pancreatitis was significantly lower than in controls [5-7]. 
Pancreatitis remains the most common severe complication of ERCP, and there are many studies that document its risk factors and prophylactic procedures. The etiology of post-ERCP pancreatitis is multifactorial, involving mechanical, chemical, hydrostatic, enzymatic, microbiologic, and thermal factors [9]. Risk factors of post-ERCP pancreatitis are divided into patient-related and procedure-related variables. Major reported risk factors of post-ERCP pancreatitis are dysfunction of the sphincter of Oddi, a history of pancreatitis, younger age, female gender, difficulties in cannulation, performance of pancreatography, trainee involvement, and therapeutic ERCP procedures, for example $[1,2,9,10]$. In some cases with difficulties in cannulation or therapeutic procedures such as endoscopic sphincterotomy or endoscopic papillary balloon dilatation, trauma or edema around the pancreatic orifice obstructs the flow of pancreatic juice, leading to the pathogenesis of pancreatitis. The incidence of acute pancreatitis was reported to be $5-20 \%$ in patients receiving endoscopic papillary balloon dilatation for common bile duct stones $[10,11]$. In this study, the estimated patency of the APD in 34 patients with post-ERCP pancreatitis was only $16 \%$, which was significantly lower than that in controls (43\%). If pancreatic juice can flow through the minor duodenal papilla as well as the major duodenal papilla, an efficient mechanism for decompressing the pancreatic duct system is available during obstruction of the main pancreatic duct near its orifice. A patent APD acts as a secondary drainage system for the main pancreatic duct, and may prevent post-ERCP pancreatitis by reducing pressure in the main pancreatic duct $[12,13]$. During diagnostic or therapeutic ERCP, in patients with the branch- or halfway-type APD, endoscopists should be more cautious than usual, and alternatively consider prophylactic pancreatic stenting. There was no relationship between the severity of post-ERCP pancreatitis and APD patency. Patency of the APD may be associated with the occurrence of post-ERCP pancreatitis, but not with its progression.

Limitations of this study are that APD patency was retrospectively estimated from previous data on the relationship between APD patency and the terminal shape of the APD obtained by dye injection ERP, and data were compared with those of controls previously analyzed using dye injection ERP.

In conclusion, the terminal shape of the APD which showed quite low patency was more frequent in patients with post-ERCP pancreatitis than in controls. There was a significantly decreased estimated patency of the APD in patients with post-ERCP pancreatitis compared with controls (16 vs. $43 \%$, respectively). A patent APD may function as a second drainage system to reduce the pressure in the main pancreatic duct and prevent post-ERCP pancreatitis.

\section{References}

1 Masci E, Toti G, Mariani A, Curioni S, Lomazzi A, Dinelli M, Minoli G, Crosta C, Comin U, Fertitta A, Prada A, Passoni GR, Testoni PA: Complications of diagnostic and therapeutic ERCP: a prospective multicenter study. Am J Gastroenterol 2001;96: 417-423.

-2 Freeman ML, DiSario JA, Nelson DB, Fennerty MB, Lee JG, Bjorkman DJ, Overby CS, Aas J, Ryan ME, Bochna GS, Shaw MJ, Snady HW, Erickson RV, Moore JP, Roel JP: Risk factors for post-ERCP pancreatitis: a prospective, multicenter study. Gastrointest Endosc 2001;54:425-434.

3 Kamisawa T, Koike M, Okamoto A: Embryology of the pancreatic duct system. Digestion 1999;60:161-165.

-4 Adda G, Hannoun L, Loygue J: Development of the human pancreas: variations and pathology. A tentative classification. Anat Clin 1984;5:275-283.

5 Kamisawa T, Tabata I, Tajima T, Tsushima T, Yoshida Y: Patency of the human accessory pancreatic duct as determined by dye-injec- tion endoscopic retrograde pancreatography. Digestion 1997;58:78-82.

-6 Kamisawa T, Tu Y, Egawa N, Ishiwata J, Okamoto A: Patency of the accessory pancreatic duct in relation to its course and shape: a dyeinjection endoscopic retrograde pancreatography study. Am J Gastroenterol 1998;93: 2135-2140.

-7 Kamisawa T, Yoshiike M, Egawa N, Nakajima H: Patency of the accessory pancreatic duct evaluated by dye-injection endoscopic retrograde pancreatography: methods and clinical implication. Dig Endosc 2004;16: 272-276.

-8 Ogawa M, Hirota M, Hayakawa T, Matsuno S, Watanabe S, Atomi Y, Otsuki M, Kashima K, Koizumi M, Harada H, Yamamoto M, Nishimori I: Development and use of a new staging system for severe acute pancreatitis based on a nationwide survey in Japan. Pancreas 2002;25:325-330.

$\checkmark 9$ Cheng CL, Sherman S, Watkins JL, Barnett J, Freeman M, Geenen J, Ryan M, Parker H, Frakes JT, Fogel EL, Silverman WB, Dua KS,
Aliperti G, Yakshe P, Uzer M, Jones W, Goff J, Lazzell-Pannell L, Rashdan A, Temkit M, Lehman GA: Risk factors for post-ERCP pancreatitis: a prospective multicenter study. Am J Gastroenterol 2006;101:139-147.

10 Arata S, Takada T, Hirata K, Yoshida M, Mayumi T, Hirota M, Yokoe M, Hirota M, Kiriyama S, Sekimoto M, Amano H, Wada K, Kimura Y, Gabata T, Takeda K, Kataoka K, Ito T, Tanaka M: Post-ERCP pancreatitis. J Hepatobiliary Pancreat Surg, E-pub ahead of print.

-11 Tsujino T, Isayama H, Komatsu Y, Ito Y, Tada M, Minagawa N, Nakata R, Kawabe T, Omata M: Risk factors for pancreatitis in patients with common bile duct stones managed by endoscopic papillary balloon dilatation. Am J Gastroenterol 2005;100:38-42.

12 Kamisawa T, Yoshiike M, Egawa N, Nakajima H: Patent accessory pancreatic duct prevent acute pancreatitis. Am J Gastroenterol 2003;98:2807-2808.

13 Kamisawa T: Clinical significance of the minor duodenal papilla and accessory pancreatic duct. J Gastroenterol 2004;39:605-615. 